\title{
Fatigue and Safety in Paramedicine
}

\author{
Elizabeth A. Donnelly, PhD, LICSW, MPH, NREMT*; Paul Bradford, MD, MDS'; \\ Matthew Davis, MD, MSc ${ }^{\ddagger}$; Cathie Hedges, AEMCA, ACP, CMM II ; Doug Socha, PCP, BSc, MAף; \\ Peter Morassutti, BSc, ACP, CMMII, NCEE, NCl, CPSO"
}

\begin{abstract}
CLINICIAN'S CAPSULE
What is known about the topic?

Previous research has linked fatigue with a safety outcome; it is unclear if this is true for Canadian paramedics. What did this study ask?

This study examined the interrelationship of fatigue and safety outcomes including injury, safety-compromising behaviors, and adverse events/medical errors.

What did this study find?

Over one-half of paramedics reported being fatigued at work; significant relationships were identified between fatigue and safety outcomes.

Why does this study matter to clinicians?

This study demonstrates fatigue is prevalent in a sample of Canadian paramedics and may influence patient and provider safety.
\end{abstract}

\section{ABSTRACT}

Objectives: Extant research has established an empirical relationship between fatigue and safety-related outcomes. It is not clear if these findings are relevant to Canadian paramedicine. The purpose of this study was to determine if fatigue and shiftwork variables were related to safety outcomes in Canadian paramedics.

Methods: A survey was conducted with ten paramedic services in Ontario with a $40.5 \%$ response rate $(n=717)$. Respondents reported levels of fatigue, safety outcomes (injury, safety compromising behaviours, and medical errors/adverse events), work patterns (types of shifts, hours worked weekly) and demographic characteristics. Univariate and logistic regression analyses were used to assess for significant differences.

Results: In this sample, $55 \%$ of paramedics reported being fatigued at work. Fatigued paramedics were over twice as likely to report injuries, three times as likely to report safety compromising behaviors, and 1.5 times more likely to report errors/ adverse outcomes. When controlling for fatigue, shift length variables did not consistently influence safety outcomes.

Conclusion: These results create preliminary evidence of a relationship between fatigue and safety outcomes in Canadian paramedicine. While more research is needed, these findings point to the influence fatigue has on safety outcomes and provide an indication that fatigue mitigation efforts may be worthwhile.

\section{RÉSUMÉ}

Objectif: D'après les travaux de recherche, il existe une relation empirique entre la fatigue et les résultats liés à la sécurité. Toutefois, on ne sait pas si les constatations s'appliquent à la paramédecine au Canada. L'étude avait donc pour but de déterminer si la fatigue et les variables relatives au travail par postes avaient une incidence sur les résultats liés à la sécurité chez les ambulanciers paramédicaux au Canada.

Méthode: Une enquête a été menée dans 10 services paramédicaux, en Ontario, et le taux de réponse a atteint 40,5\% ( $n=$ 717). Les participants devaient faire état du degré de fatigue, de résultats liés à la sécurité (blessure, comportements mettant en péril la sécurité, erreurs médicales et effets indésirables), du régime de travail (type de roulement, nombre d'heures de travail par semaine) et de données démographiques. Des analyses de régression logistique et unidimensionnelle ont été effectuées afin de mettre en évidence des écarts importants.

Résultats: Dans l'échantillon étudié, $55 \%$ des ambulanciers paramédicaux ont déclaré ressentir de la fatigue au travail. Ceux-ci étaient plus de deux fois susceptibles de subir des blessures, trois fois plus susceptibles d'avoir des comportements mettant en péril la sécurité et une fois et demie plus susceptibles de déclarer des erreurs ou des effets indésirables. Par ailleurs, lorsqu'on tenait compte de la fatigue, les variables

From the *University of Windsor, School of Social Work, Windsor, ON; †Department of Emergency Medicine Windsor Regional Hospital, University of Western Ontario, Southwest Ontario Regional Base Hospital Program, London, ON; ¥Division of Emergency Medicine, University of Western Ontario, Southwest Ontario Regional Base Hospital Program, London, ON; §Captain-Professional Standards, Essex Windsor EMS, Essex, ON; ॠChief-Hastings-Quinte Paramedic Services, Belleville, ON; and „Pre-hospital Care Specialist, Southwest Ontario Regional Base Hospital Program-Windsor Site, Tecumseh, ON.

Correspondence to: Dr. Elizabeth A. Donnelly, University of Windsor, School of Social Work, 401 Sunset Avenue, Windsor, ON N9B 3P4; Email: donnelly@uwindsor.ca

(c) Canadian Association of Emergency Physicians

CJEM 2019;21(6):762-765

DOI 10.1017/cem.2019.380 
relatives à la durée des postes de travail n'avaient pas la même incidence sur les résultats liés à la sécurité.

Conclusion: Les résultats fournissent des données préliminaires sur l'existence d'une relation entre la fatigue et les résultats liés à la sécurité en paramédecine au Canada. Si le sujet demande à être approfondi, les constations font déjà ressortir l'incidence de la fatigue sur les résultats liés à la sécurité ainsi que la pertinence de trouver des moyens d'atténuation de la fatigue.

Keywords: Prehospital/EMS, public health, safety

\section{INTRODUCTION}

Previous research with paramedics has illustrated an empirical link between fatigue and safety-related outcomes. Specifically, fatigued paramedics are 1.9 times more likely to be injured at work, 2.2 times more likely to experience an adverse event or medical error (e.g., accidentally dislodging an endotracheal tube and not checking a glucose level in a patient with altered mental status), and 3.6 times more likely to engage in safetycompromising behaviour (e.g., exceeding the speed limit while driving non-emergently, drinking alcohol within eight hours of starting a shift, or failing to restock the ambulance). ${ }^{1}$ It is not yet clear if this research linking fatigue and safety outcomes is relevant to Canadian paramedicine. Additionally, some research has suggested that shift structure may impact paramedics. ${ }^{2}$ Therefore, in this study, we addressed the following research questions:

1. Does a relationship between fatigue and safety outcomes exist in the context of Canadian paramedicine?

2. Controlling for fatigue, what relationship exists among shift length, hours worked weekly, shift type, and safety outcomes?

\section{METHODS}

Paramedic services were recruited through a listserv of chiefs of paramedic services in Ontario. Of the 54 paramedic services in Ontario, 10 services consented to participate. Respondents were contacted using their work emails, which were provided by the employers; responses were held confidentially and only reported in aggregate. Respondents received an introductory email, followed by two invitations and two reminders. ${ }^{3}$ Data collection occurred in 2015. Respondents reported levels of fatigue using the Chalder Fatigue Scale, an 11-item scale with a score of $>4$ indicated fatigue. ${ }^{4}$ Safety outcomes were measured using an adapted version of the American EMS (emergency medical services) Safety Inventory, an instrument which asks respondents to report if they had been injured, engaged in safety compromising behaviors, or made medical errors or had adverse outcomes in the past three months. ${ }^{1}$ The inventory was reviewed and adapted for Canadian practice (e.g., a question regarding "miles per hour" was changed to "kilometers per hour"). Respondents also reported shift length, shift type (days, nights, and rotate), hours worked weekly, and demographic characteristics. A follow-up survey was conducted to assess for significant differences among responders and non-responders (paramedics who did not respond to the survey and did not opt out of participation). Analyses were conducted using SPSS (v. 24). Univariate statistics were used to describe the sample; logistic regression was used to test the hypotheses.

\section{RESULTS}

The sampling frame for this survey was 1,767 paramedics. The survey had a total of 825 responses; 108 respondents did not complete at least $80 \%$ of the survey and were not included in the analyses, ${ }^{6}$ resulting in a $40.5 \%$ usable response rate $(n=717)$. Appendix A describes the demographics of the sample; the demographics in this study are comparable to other recent studies of Canadian paramedics. ${ }^{7,8}$ The Chalder Fatigue scale behaved reliably $(\alpha=0.79)$.

For the purposes of these analyses, the safety outcome variables were dichotomized (those who endorsed any event were coded as 1 ; negative responses were coded 0 ). Fatigue was also dichotomized. In this sample, $55 \%$ of paramedics reported being fatigued at work. In the past three months, $33.5 \%$ of paramedics reported injury, $96.2 \%$ engaged in safety-compromising behavior, and $66.3 \%$ had a medical error or adverse event. Respondents reported most frequently working between 41 and 60 
hours (71\%), working 12-hour shifts (93\%), and rotating shifts between days and nights (75.7\%).

The research questions were tested using bivariate analyses, followed by a multivariate analysis. The results are presented in Table 1.

Bivariate analyses are included in Appendix B. Multivariate logistic regressions were conducted to determine which variables were the best predictors of the safety outcomes. Model fit was assessed using Nagelkerke R2. In all three models, fatigue remained a significant predictor of safety outcomes. Controlling for fatigue, shift length variables did not retain a consistently significant relationship with safety outcomes. Rotating shifts approached significance in predicting injury but did not meet the $p$ of $<0.05$ threshold. Working more than 40 hours a week remained a significant predictor of safety-compromising behavior. Shift length was a significant predictor of errors/adverse events. Few demographic differences in safety outcomes were identified; age was the only significant predictor in any of the multivariate models and was only related to errors.

A total of 69 responses to the follow-up survey were received from nine paramedic services. No significant differences were found in age $(\mathrm{t}[769]=0.498, p=0.62)$, years in paramedicine $(\mathrm{t}[753]=1.02, \mathrm{p}=0.31)$, gender $\left(\chi^{2}=0.74[3], p=0.86\right)$, and level of certification $\left(\chi^{2}=\right.$ $0.12[1], p=0.72)$.

\section{LIMITATIONS}

As with all cross-sectional surveys, structural limitations must be noted. This study was limited by the number of services that consented to participate, that all participating services were in Ontario, and the low response rate to the survey. These considerations limit the generalizability of the findings. While the response rate was low, it is higher than response rates typically found in email-based surveys. Further, there was clear delineation of the sampling frame (often not available in internet-based surveys). Further limitations may be associated with social desirability and recall biases, in which respondents reported what they thought was the preferred answer or were unable to remember accurately within the threemonth time frame. A lack of variability in the shift length variable limited its utility. Finally, although the

\begin{tabular}{|c|c|c|c|}
\hline & \multicolumn{3}{|c|}{ Injury } \\
\hline & $\beta$ & OR & $95 \% \mathrm{Cl}$ \\
\hline Fatigued & 0.76 & $2.13^{\dagger}$ & $1.54-2.96$ \\
\hline Shift length (12+ hours) & N/S - excluded & & \\
\hline Rotate shifts & 0.35 & $1.42(p=0.077)$ & $0.96-2.08$ \\
\hline Worked \pm 40 hours weekly & N/S - excluded & & \\
\hline \multirow[t]{3}{*}{ Level of certification } & N/S - excluded & & \\
\hline & \multicolumn{3}{|c|}{ Safety-compromising behaviors } \\
\hline & $\beta$ & OR & $95 \% \mathrm{Cl}$ \\
\hline Fatigued & 1.19 & $3.27 *$ & $1.27-8.47$ \\
\hline Shift length (12+ hours) & N/S - excluded & & \\
\hline Rotate shifts & N/S - excluded & & \\
\hline \multirow[t]{3}{*}{ Worked \pm 40 hours weekly } & 1.78 & $5.90^{\dagger}$ & $2.54-13.74$ \\
\hline & \multicolumn{3}{|c|}{ Errors and adverse events } \\
\hline & $\beta$ & OR & $95 \% \mathrm{Cl}$ \\
\hline Fatigued & 0.41 & $1.50^{*}$ & $1.06-2.11$ \\
\hline Shift length (12+ hours) & 1.13 & $3.01 *$ & $1.31-7.26$ \\
\hline Rotate shifts & N/S - excluded & & \\
\hline Worked \pm 40 hours weekly & N/S - excluded & & \\
\hline Length of service & N/S - excluded & & \\
\hline Age & -0.04 & $0.958^{\dagger}$ & $0.94-0.97$ \\
\hline
\end{tabular}


confidentiality of their responses was emphasized, respondents might have underreported events because of a fear of reprisal or variability in safety culture. ${ }^{9}$

\section{DISCUSSION}

The primary purpose of this research was to explore if extant findings related to fatigue and safety outcomes were relevant for Canadian paramedicine. These data illustrate that fatigue is related to safety outcomes. In previous research in American paramedics, 55\% of the sample was fatigued; this proportion was mirrored in the Canadian sample. ${ }^{1}$ Further, the relationship between fatigue and safety outcomes remains significant, insofar as fatigued paramedics in this sample were far more likely to report negative safety outcomes than non-fatigued paramedics. ${ }^{1}$ This study was also able to provide some early evidence that working over 40 hours weekly had a relationship to safety outcomes. While the impact of shift work on safety has been identified in paramedicine elsewhere, ${ }^{2}$ this finding of a significant relationship between hours worked and safety outcomes is unique in Canadian paramedicine.

These results provide initial evidence of a link between fatigue and safety in Canadian paramedicine. Larger studies are warranted to discover if these findings are relevant to Canadian paramedics nationally. Further, future work should broaden the investigation into factors that might influence safety, so that a greater number of modifiable factors may be identified. Operationally, fatigue mitigation efforts may be beneficial in protecting the safety of both paramedics and their patients. The recent release of an empirically sound set of recommendations for fatigue mitigation in paramedics ${ }^{10}$ is an excellent resource and will provide a framework for intervention. The safety of paramedics is critical as a workforce health issue; the safety of their patients is a public health concern. These studies are necessary insofar as it illustrates the factors that might pose a risk to the health and wellbeing of paramedics, as well as the general public. Research is the first step in the necessary process of working to increase the health of paramedics and the communities they serve.

Supplementary material: The supplementary material for this article can be found at https://doi.org/10.1017/cem.2019.380.

Acknowledgements: The authors would like to gratefully acknowledge the financial support of the Paramedic Chiefs of Canada as well as Chief Bruce Krauter and Essex-Windsor EMS, who were our valued community partners in this research. We further wish to thank all the paramedic services and paramedics for their participation.

\section{REFERENCES}

1. Patterson PD, Weaver MD, Frank RC, et al. Association between poor sleep, fatigue, and safety outcomes in emergency medical services providers. Prehosp Emerg Care 2011;16(1):86-97.

2. Patterson PD, Runyon MS, Higgins JS, et al. Shorter versus longer shift durations to mitigate fatigue and fatigue-related risks in emergency medical services personnel and related shift workers: a systematic review. Prehosp Emerg Care 2018;22(sup1):28-36.

3. Dillman DA. Mail and Internet surveys: The tailored design method. 2nd ed. New York: John Wiley \& Sons; 2007.

4. Chalder T, Berelowitz G, Pawlikowska T, et al. Development of a fatigue scale. 7 Psychosom Res 1993;37(2):147-53.

5. IBM Corp. IBM SPSS Statistics for Windows, Version 24.0. Armonk, NY: IBM Corp; Released 2016.

6. Hertel BR. Minimizing error variance introduced by missing data routines in survey analysis. Sociol Methods Res 1976;4 (4):459-74.

7. Fischer SL, MacPhee RS. Canadian paramedic health and wellness project: Workforce profile and health and wellness trends. Ottawa: Defence Research and Development Canada; 2017.

8. Bigham BL, Jensen JL, Tavares $W$, et al. Paramedic selfreported exposure to violence in the emergency medical services (EMS) workplace: A mixed-methods cross-sectional survey. Prehosp Emerg Care 2014;18(4):489-94.

9. Probst TM. Organizational safety climate and supervisor safety enforcement: multilevel explorations of the causes of accident underreporting. F Appl Psychol 2015;100(6):1899-907.

10. Patterson PD, Higgins JS, Van Dongen HPA, et al. Evidence-based guidelines for fatigue risk management in emergency medical services. Prehosp Emerg Care 2018;22 (sup1):89-101. 